\title{
Sex-specific impact of early-life adversity on chronic pain: a large population-based study in Japan
}

\author{
Keiko Yamada ${ }^{1,2}$ \\ Ko Matsudaira ${ }^{3,4}$ \\ Eizaburo Tanaka ${ }^{1,5}$ \\ Hiroyuki Oka ${ }^{3}$ \\ Junji Katsuhira ${ }^{3,6}$ \\ Hiroyasu Iso'
}

'Public Health, Department of Social Medicine, Osaka University Graduate School of Medicine, Suita, Osaka, ${ }^{2}$ Center for Pain Management, Osaka University Hospital, Suita, Osaka, ${ }^{3}$ Department of Medical Research and Management for Musculoskeletal Pain, 22nd Century Medical and Research Center, Faculty of Medicine, The University of Tokyo, Tokyo, ${ }^{4}$ Japan Labour Health \& Welfare Organization, Tokyo, ${ }^{5}$ Hyogo Institute for Traumatic Stress, Kobe, ${ }^{6}$ Department of Prosthetics \& Orthotics and Assistive Technology, Faculty of Medical Technology, Niigata University of Health and Welfare, Niigata, Japan
Correspondence: Hiroyasu Iso Public Health, Department of Social Medicine, Graduate School of Medicine, Osaka University, 2-2 Yamadaoka, Suita, Osaka 565-087I, Japan

Tel +8I 6687939 II

Fax +81668793919

Email iso@pbhel.med.osaka-u.ac.jp
This article was published in the following Dove Press journal:

Journal of Pain Research

16 February 2017

Number of times this article has been viewed

Background: Responses to early-life adversity may differ by sex. We investigated the sex-specific impact of early-life adversity on chronic pain, chronic multisite pain, and somatizing tendency with chronic pain.

Methods: We examined 4229 respondents aged 20-79 years who participated in the Pain Associated Cross-Sectional Epidemiological Survey in Japan. Outcomes were: 1) chronic pain prevalence, 2) multisite pain ( $\geq 3$ sites) prevalence, and 3) multiple somatic symptoms ( $\geq 3$ symptoms) among respondents with chronic pain related to the presence or absence of early-life adversity.

Multivariable-adjusted odds ratios (ORs) were calculated with 95\% confidence intervals using a logistic regression model including age, smoking status, exercise routine, sleep time, body mass index, household expenditure, and the full distribution of scores on the Mental Health Inventory-5. We further adjusted for pain intensity when we analyzed the data for respondents with chronic pain.

Results: The prevalence of chronic pain was higher among respondents reporting the presence of early-life adversity compared with those reporting its absence, with multivariable ORs of $1.62(1.22-2.15, p<0.01)$ in men and $1.47(1.13-1.90, p<0.01)$ in women. Among women with chronic pain, early-life adversity was associated with multisite pain and multiple somatic symptoms; multivariable ORs were $1.78(1.22-2.60, p<0.01)$ for multisite pain and $1.89(1.27-2.83$, $p<0.01$ ) for $\geq 3$ somatic symptoms. No associations were observed between early-life adversity and chronic multisite pain or multiple somatic symptoms among men with chronic pain.

Conclusion: Early-life adversity may be linked to a higher prevalence of chronic pain among both sexes and to multisite pain and somatizing tendency among women with chronic pain.

Keywords: sex characteristics, early-life adversity, chronic pain, somatoform disorders, disaster

\section{Introduction}

Early-life adversity (ELA) is defined as traumatic experiences during childhood encompassing maltreatment, accidents, death of a close relative, and disaster, any of which could have an influence not only in childhood but also in later life in the form of difficulties such as posttraumatic stress disorder (PTSD) or irritable bowel syndrome. ${ }^{1,2}$ Previous studies have also described the relationship between ELA events and chronic pain (e.g., low back pain or fibromyalgia), but most of these studies were small-scale or targeted to North American, European, Oceanian populations, ${ }^{3-7}$ and once targeted to Japanese population. ${ }^{8}$

This study focuses on the effects of ELA as a broader concept in relation to chronic pain. We used a question about adverse life events in general, rather than specific adversities. 
Various sex or gender differences in tolerance for stressful life events have been documented. For example, a meta-analytic review revealed that women reported more symptoms of depression and anxiety than did men, but that the sex difference in psychological symptoms accounted for only about $4 \%$ of the variance in sex differences in reports of stress. ${ }^{9}$ Sex or gender differences as they relate to chronic pain have been discussed for decades. The prevalence of chronic pain among women is higher than that among men, ${ }^{10,11}$ and somatic symptoms have been reported by women than by men. ${ }^{12,13}$

We hypothesized that ELA would have long-term adverse impact, which manifested as chronic pain on more women than men, so we investigated the sex-specific association between ELA and the prevalence of chronic pain, chronic multisite pain, and somatizing tendency complicated by chronic pain in a large population-based study of Japanese men and women aged 20-79 years.

\section{Methods}

\section{Ethical provisions}

All procedures followed were in accordance with the ethical standards of the Helsinki Declaration of 1975 as revised in 2000. The institutional review boards of Keio University and of the Japan Labour Health and Welfare Organization approved this study. All participants had given their written informed consent before responding to the questionnaire. A credit point for Internet shopping was given as an incentive to the respondents.

\section{Study population}

The Pain Associated Cross-Sectional Epidemiological (PACE) study was a web-based survey designed to evaluate pain in a large Japanese population using a self-reported questionnaire. The PACE survey was conducted from 10 to 18 January 2009. The data set was the same as in previous PACE studies, profiles of which have been reported elsewhere; ${ }^{14,15}$ however, the aim of this study was completely different from that of previous studies. Figure 1 shows the sampling procedure that culminated in the sample analyzed in the present study. A total of 20,044 respondents $(9,746$ men and 10,298 women) aged 20-79 years and matching the Japanese demographic composition in 2007 (Japanese Ministry of Internal Affairs and Communications, 2007) were recruited by e-mail from 1,477,585 candidates who registered with an Internet survey company (Rakuten Research, Inc., Tokyo, Japan). Computer-generated invitational e-mails were sent with a link to the first questionnaire until the targeted sample number was achieved. Incomplete questionnaires were rejected automatically, so the response rate was not calculated. The first questionnaire included items on age, sex, and pain, and was completed by 20,044 respondents. Subsequently, detailed questionnaires about lifestyle and psychosocial factors were sent to 5,000 of these respondents. Half $(2,500)$ were chosen from those who had reported pain on the first questionnaire; the other half had reported being pain-free. The profile of these 5,000 respondents was consistent with the Japanese demographic composition for sex and age in $2007 .{ }^{16} \mathrm{~A}$ total of 5,000 participants responded to the second questionnaire. Of these, we drew the data on 4,229 individuals (1,729 with chronic pain and 2,500 without pain) in the analyses. Moreover, the respondents with chronic pain were included in some additional analyses.

\section{Definitions and measures}

\section{Chronic pain}

The first questionnaire included items on pain such as the pain sites, pain intensity at each site, the site of dominant pain, and the duration of dominant pain. Pain intensities were scored on an 11-point Numerical Rating Scale (NRS; 0=no pain, $10=$ worst pain imaginable). In accord with the definition of chronic pain from the International Association for the Study of Pain, participants reported persistent pain over 3 months. ${ }^{17}$

\section{Early-life adversity}

We used a simple yes/no question to detect ELA, "Did you have any mentally shocking events (e.g., accidents experienced by you or close relatives, death of close relatives or friends, disaster, injury from violence) when you were 14 years old or younger?".

\section{Multisite pain}

The questionnaire included a picture of a human form with its body parts numbered from 1 to 21 , and respondents entered the number(s) that corresponded to their pain site(s). A count of pain sites is a simple and useful measure for the severity of chronic pain, and chronic multisite pain is a strong predictor of future disability. ${ }^{18}$ We defined more than three pain sites as multisite pain in the current study.

\section{Somatizing tendency}

Somatic symptom disorder involves having physical symptoms such as fatigue or dizziness caused by major emotional distress and problems functioning. ${ }^{19}$ The disorder decreases its sufferers' quality of life. The Brief Symptom Inventory (BSI) is a self-reported measure of somatic symptoms, in which respondents answer on a 5-point Likert-type scale, 
$1,477,585$ candidates registered by the Internet survey company
Invitation e-mails containing a link to the first questionnaire were sent by computer system until the targeted sample number was achieved. Incomplete questionnaires were rejected automatically

Matching the Japanese demographic composition for sex and age in 2007 by computer system automatically

The first questionnaire

(9,746 men and 10,298 women aged $20-79$ years)

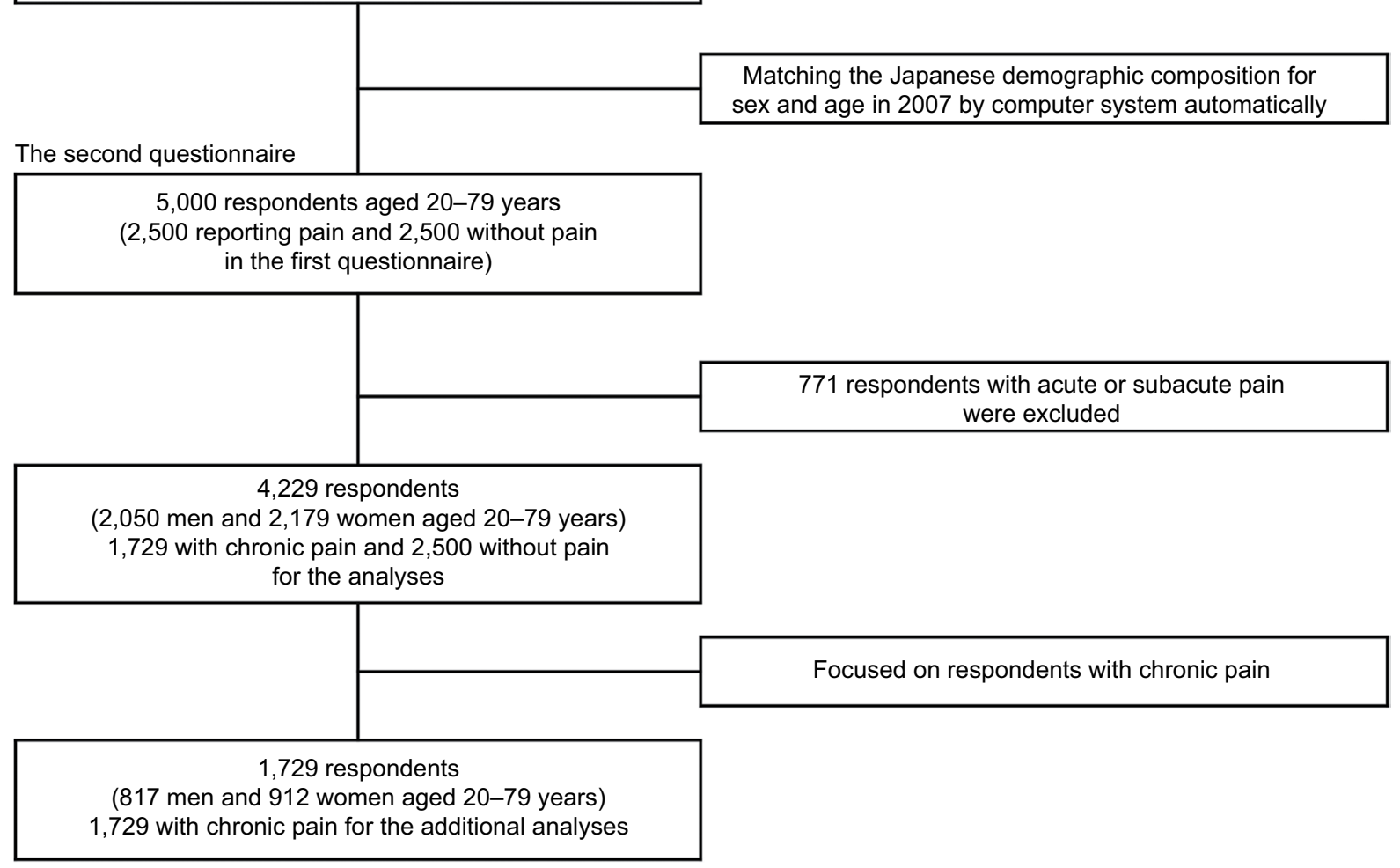

Figure I Flowchart of the sampling procedure ending in the sample being analyzed in the current study.

ranging from 0 (not at all) to 4 (extremely), regarding each of seven symptoms during the past 7 days: faintness or dizziness, pain in the heart or chest, nausea or upset stomach, trouble catching one's breath, numbness or tingling in parts of one's body, feeling weak in parts of one's body, and hot or cold spells. ${ }^{20}$ Endorsing a response of 2, 3, or 4 was considered presence of the symptom. The number of symptoms with this level of response was counted; the totals ranged from zero to seven symptoms. We defined respondents with $\geq 3$ symptoms, the highest tertile of the symptom count in our data, as existence of the somatizing tendency.

\section{Mental status}

We used the Mental Health Inventory (MHI-5), which is identical to the 36-item Short Form Health Survey (SF-36) "Mental Health" domain, to measure mental status. ${ }^{21,22}$ The MHI-5 includes the following five questions: "How much of the time during the last month have you: 1) been a very nervous person?,
2) felt downhearted and blue?, 3) felt calm and peaceful?, 4) felt so down in the dumps that nothing could cheer you up?, and 5) been a happy person?". The respondents choose a number from 1 (all of the time) to 6 (none of the time). ${ }^{21}$ The total score, which ranges from 5 to 30 points, is converted to a 100-point scale. ${ }^{21}$ A previous Japanese study validated the cut point of $<52$ on the MHI-5 as screening for severe depressive symptoms. ${ }^{21}$

\section{Statistical analysis}

A Student's $t$-test was conducted to test for differences in age-adjusted mean values and proportions of risk factors for chronic pain. A chi-square test was performed to test for sex differences in the proportion of ELA.

Three outcomes were measured in the current study, 1) chronic pain prevalence among all respondents, 2) chronic multisite pain ( $\geq 3$ sites) prevalence, and 3) multiple somatic symptoms ( $\geq 3$ symptoms) among respondents with chronic pain, as these variables related to the presence or absence of ELA. 
Multivariable-adjusted odds ratios (ORs) with 95\% confidence intervals (CIs) were calculated using a logistic regression model to compare respondents with and without ELA.

$p$-Values $<0.05$ for two-tailed tests were considered statistically significant. All statistical analyses were performed using SAS version 9.4 (SAS Institute, Inc., Cary, NC, USA).

\section{Confounding variables}

We adjusted all analyses for the following confounding variables: age, smoking status (never, ex-smoker, or current smoker), have an exercise routine (exercise longer than 30 minutes more than twice a week; yes or no), sleep time (hours/ day), body mass index $\left(\mathrm{kg} / \mathrm{m}^{2}\right.$, categorized in quintiles), household expenditure (JPY/month), and the full distribution of scores on the MHI-5.

We further adjusted for pain intensity (the NRS that ranged from 0 to 10 , i.e., $0=$ no pain, $10=$ worst pain imaginable) when we analyzed the data for respondents with chronic pain.

\section{Results}

Table 1 shows age-adjusted mean values of chronic pain risk factors according to the existence of ELA. Men with ELA were older (52.0 vs. 47.9 years), were more likely to have an exercise routine ( $45.9 \%$ vs. $33.7 \%$ ), had a higher prevalence of body mass index $\geq 25$ (31.8\% vs. $24.8 \%$ ), had higher household expenditures (380,000 vs. 293,000 JPY/month), had a higher proportion of severe depressive symptoms $(27.3 \% \mathrm{vs}$. $19.5 \%$ ), and had a higher prevalence of chronic pain $(53.7 \%$ vs. $38.0 \%$ ) compared with those who did not report ELA. Women with ELA had a higher prevalence of body mass index $\geq 25$ (20.7\% vs. $11.9 \%$ ), severe depressive symptoms (38.5\% vs. $20.2 \%)$, chronic pain $(55.0 \%$ vs. $39.7 \%)$, and severe intensity of pain $(6.5 \%$ vs. $6.1 \%)$ compared with those without it.

The prevalence of ELA was higher in women than in men (14.2\% of women, $11.8 \%$ of men; $p<0.01$ ).

Multivariable-adjusted ORs of chronic pain prevalence of respondents with ELA are shown in Table 2. Multivariableadjusted OR of chronic pain prevalence of men with ELA was $1.62(1.22-2.15, p<0.01)$, and that of women with ELA was $1.47(1.13-1.90, p<0.01)$.

Table 3 indicates multivariable-adjusted ORs of multisite pain ( $\geq 3$ sites) among chronic pain sufferers with ELA. ELA was associated with higher risk for multisite pain among female chronic pain patients: multivariable-adjusted OR was $1.78(1.22-2.60, p<0.05)$. However, there was no such association for men: multivariable-adjusted OR was 1.38 $(0.88-2.16, p=0.26)$.
Table I Age-adjusted mean values and proportions of chronic pain risk factors

\begin{tabular}{|c|c|c|}
\hline Chronic pain risk factors & $\begin{array}{l}\text { Early-life } \\
\text { adversity (-) }\end{array}$ & $\begin{array}{l}\text { Early-life } \\
\text { adversity }(+)\end{array}$ \\
\hline \multicolumn{3}{|l|}{ Men } \\
\hline$n=2,050$ & $\mathrm{I}, 808$ & 242 \\
\hline Age, years, mean (SE) & $47.9(0.4)$ & $52.0(1.0)^{*}$ \\
\hline Current smoker, \% & 27.8 & 28.1 \\
\hline Have an exercise habit, \% & 33.7 & $45.9 * *$ \\
\hline Sleep time $<5$ hours, $\%$ & 3.4 & 5.0 \\
\hline Body mass index $\geq 25, \%$ & 24.8 & $31.8^{* * *}$ \\
\hline Household expenditure $(* 10,000$ & 29.3 & $38.0^{* * *}$ \\
\hline \multicolumn{3}{|l|}{ JPY/month) } \\
\hline Severe depressive symptoms, \% & 19.5 & $27.3^{*}$ \\
\hline $\begin{array}{l}\text { Chronic pain, \% (no. of respondents } \\
\text { with chronic pain=817) }\end{array}$ & 38.0 & $53.7^{*}$ \\
\hline $\begin{array}{l}\text { Intensity of pain among respondents } \\
\text { with chronic pain }(0-10 \text { scale })\end{array}$ & 5.7 & 5.7 \\
\hline \multicolumn{3}{|l|}{ Women } \\
\hline$n=2,179$ & $\mathrm{I}, 870$ & 309 \\
\hline Age, years, mean (SE) & $48.8(0.4)$ & $49.0(0.9)$ \\
\hline Current smoker, \% & 14.9 & 18.4 \\
\hline Have an exercise habit, \% & 29.0 & 33.3 \\
\hline Sleep time $<5$ hours, $\%$ & 2.5 & 3.6 \\
\hline Body mass index $\geq 25, \%$ & 11.9 & $20.7^{*}$ \\
\hline $\begin{array}{l}\text { Household expenditure }(* 10,000 \\
\text { JPY/month) }\end{array}$ & 27.1 & 25.5 \\
\hline Severe depressive symptoms, $\%$ & 20.2 & $38.5^{*}$ \\
\hline $\begin{array}{l}\text { Chronic pain, \% (no. of respondents } \\
\text { with chronic pain=9|2) }\end{array}$ & 39.7 & $55.0^{*}$ \\
\hline $\begin{array}{l}\text { Intensity of pain among respondents } \\
\text { with chronic pain }(0-10 \text { scale })\end{array}$ & 6.1 & $6.5^{* * * *}$ \\
\hline
\end{tabular}

Notes: Test for significance difference from the category of no early-life adversity: ${ }^{*} p<0.001, * * p<0.01$, *** $p<0.05$.

Abbreviation: SE, standard error.

Table 2 ORs and $95 \% \mathrm{Cls}$ of chronic pain prevalence of respondents with early-life adversity

\begin{tabular}{|c|c|c|}
\hline & $\begin{array}{l}\text { Early-life } \\
\text { adversity (-) }\end{array}$ & $\begin{array}{l}\text { Early-life } \\
\text { adversity (+) }\end{array}$ \\
\hline \multicolumn{3}{|l|}{ Men } \\
\hline Number of respondents at risk & 2,172 & 294 \\
\hline $\begin{array}{l}\text { Number of respondents with } \\
\text { chronic pain }\end{array}$ & 687 & 130 \\
\hline Age-adjusted OR (95\% Cl) & 1.00 & $1.86(1.42-2.43)^{*}$ \\
\hline Multivariable-adjusted OR $(95 \% \mathrm{Cl})$ & 1.00 & $1.62(1.22-2.15)^{* *+}$ \\
\hline \multicolumn{3}{|l|}{ Women } \\
\hline Number of respondents at risk & 2,178 & 356 \\
\hline $\begin{array}{l}\text { Number of respondents with } \\
\text { chronic pain }\end{array}$ & 742 & 170 \\
\hline Age-adjusted OR $(95 \% \mathrm{Cl})$ & 1.00 & $1.86(1.46-2.37)^{*}$ \\
\hline Multivariable-adjusted OR $(95 \% \mathrm{Cl})$ & 1.00 & $1.47(1.13-1.90)^{* *}$ \\
\hline
\end{tabular}

Notes: ORs are adjusted for age, smoking status, exercise routine, sleep time, body mass index, personal consumption expenditure, and the full distribution of scores on the Mental Health Inventory-5. Test for significant difference from the category of no early-life adversity: ${ }^{*} p<0.00 \mathrm{I},{ }^{* *} p<0.01$.

Abbreviations: $\mathrm{Cl}$, confidence interval; OR, odds ratio. 
Table 3 ORs and $95 \% \mathrm{Cls}$ for multisite pain in chronic pain sufferers with early-life adversity

\begin{tabular}{|c|c|c|}
\hline & $\begin{array}{l}\text { Early-life } \\
\text { adversity (-) }\end{array}$ & $\begin{array}{l}\text { Early-life } \\
\text { adversity (+) }\end{array}$ \\
\hline \multicolumn{3}{|l|}{ Men } \\
\hline Number of chronic pain sufferers & 687 & 130 \\
\hline Number of chronic pain sufferers & 283 & 59 \\
\hline \multicolumn{3}{|l|}{ with multisite pain $(\geq 3)$} \\
\hline Age-adjusted OR (95\% Cl) & 1.00 & $1.57(1.06-2.34)^{* * *}$ \\
\hline Multivariable-adjusted OR $(95 \% \mathrm{Cl})$ & 1.00 & $1.38(0.88-2.16)$ \\
\hline \multicolumn{3}{|c|}{ Women } \\
\hline Number of chronic pain sufferers & 742 & 170 \\
\hline $\begin{array}{l}\text { Number of chronic pain sufferers } \\
\text { with multisite pain }(\geq 3)\end{array}$ & 379 & 117 \\
\hline Age-adjusted OR $(95 \% \mathrm{Cl})$ & 1.00 & $2.27(1.62-3.18)^{*}$ \\
\hline Multivariable-adjusted OR $(95 \% \mathrm{Cl})$ & 1.00 & $1.78(1.22-2.60)^{* * *}$ \\
\hline
\end{tabular}

Notes: Adjusted for age, smoking status, exercise routine, sleep time, body mass index, household expenditure, the full distribution of scores on the Mental Health Inventory-5, and intensity of pain.Test for significant difference from the category of no early-life adversity: ${ }^{*} p<0.001, * * p<0.01$, $* * * p<0.05$.

Abbreviations: $\mathrm{Cl}$, confidence interval; $\mathrm{OR}$, odds ratio.

Table 4 ORs and $95 \% \mathrm{Cls}$ for multiple somatic symptoms among chronic pain sufferers with early-life adversity versus no early-life adversity

\begin{tabular}{|c|c|c|}
\hline & $\begin{array}{l}\text { Early-life } \\
\text { adversity (-) }\end{array}$ & $\begin{array}{l}\text { Early-life } \\
\text { adversity (+) }\end{array}$ \\
\hline \multicolumn{3}{|l|}{ Men } \\
\hline Number of chronic pain sufferers & 687 & 130 \\
\hline $\begin{array}{l}\text { Number of multiple somatic } \\
\text { symptoms }(\geq 3)\end{array}$ & 283 & 59 \\
\hline Age-adjusted OR (95\% Cl) & 1.00 & $1.57(1.06-2.34)^{* * *}$ \\
\hline Multivariable-adjusted OR $(95 \% \mathrm{Cl})$ & 1.00 & $1.27(0.83-1.94)$ \\
\hline \multicolumn{3}{|c|}{ Women } \\
\hline Number of chronic pain sufferers & 742 & 170 \\
\hline $\begin{array}{l}\text { Number of multiple somatic } \\
\text { symptoms }(\geq 3)\end{array}$ & 379 & 117 \\
\hline Age-adjusted OR $(95 \% \mathrm{Cl})$ & 1.00 & $2.10(1.46-3.00)^{*}$ \\
\hline Multivariable-adjusted OR $(95 \% \mathrm{Cl})$ & 1.00 & $1.89(1.27-2.83)^{* *}$ \\
\hline
\end{tabular}

Notes: Adjusted for age, smoking status, exercise routine, sleep time, body mass index, household expenditure, the full distribution of scores on the Mental Health Inventory-5, and intensity of pain. Test for significant difference from the category of no early-life adversity: $* p<0.001, * * p<0.01$, $* * * p<0.05$.

Abbreviations: $\mathrm{Cl}$, confidence interval; $\mathrm{OR}$, odds ratio.

In Table 4, ORs of multiple somatic symptoms ( $\geq 3$ symptoms) for ELA among chronic pain sufferers are shown. The multivariable-adjusted OR of multiple somatic symptoms was 1.89 (1.27-2.83, $p<0.01)$ for women with ELA. For men, ELA was not associated with somatic symptoms.

\section{Discussion}

The aim of this study was to examine the sex-specific impact of ELA on chronic pain, chronic multisite pain, and somatizing tendency with chronic pain. We hypothesized that ELA would have long-term adverse impact, which manifested as chronic pain on more women than men. The association of ELA with chronic multisite pain and with somatizing tendency among chronic pain sufferers supported our hypothesis. Although the significant associations were observed in women only, there was no sex difference in the association of ELA with the prevalence of chronic pain. Data from the Adverse Childhood Experience (ACE) study, which included 17,337 adults in the USA, also showed that ELA was associated with the prevalence of headache and with more frequent headaches in women than in men. ${ }^{23}$

ELA may reduce the volume of the hippocampus and prefrontal cortex; this reduction has been linked to major depression and to trait anxiety in adulthood, and predicts sensitivity to future stress events. ${ }^{24,25}$ A magnetic resonance imaging study showed that 38 patients with chronic back pain and 30 patients with complex regional pain syndrome had a significantly smaller volume of bilateral hippocampal tissue than those of 50 healthy volunteers, whereas 20 patients with osteoarthritis did not. ${ }^{26}$ Additionally, mice with neuropathic pain, in comparison with sham mice, showed more cellular and molecular changes linked to reduction of hippocampal function, ${ }^{26}$ so reduction in the volume of the hippocampus due to ELA may actually cause chronic pain.

Moreover, sex differences in central sensitization could support our results. Central sensitization is the phenomenon in which nociceptive pain input from the peripheral nervous system triggers a prolonged but reversible synaptic change of pain pathways in the central nervous system. ${ }^{27}$ Central sensitization contributes to the development of persistent pain hypersensitivity, spreads pain sensitivity across peripheral nerve territories without inflammation, ${ }^{27}$ and amplifies pain from rheumatoid arthritis, osteoarthritis, fibromyalgia, and headache, as well as neuropathic pain, complex regional pain syndrome, and postsurgical pain. ${ }^{27}$ Sex differences in enhanced pain sensitivity among patients with symptomatic knee osteoarthritis have been reported. ${ }^{28}$

In a psychological approach to chronic pain patients, especially women complaining of multisite pain or exhibiting somatizing tendencies, an intervention that addresses ELA should be considered.

\section{Limitations}

There were some limitations in this study. First, recall bias could exist because the current study was a cross-sectional design. The fact that people with persistent chronic pain are more likely to recall their ELA has been documented elsewhere. ${ }^{29}$ Second, we used a simple and unvalidated question on ELA. A previous study of ELA among adolescents used a semi-structured interview that had good inter-rater reliability, and that study reported an association between ELA and depression. ${ }^{30}$ Like that study, the current investigation concluded that respondents 
with ELA showed a higher prevalence of depressive syndrome than did those without it. We believe that our single item on ELA was an appropriate proxy for the validated questionnaire. Third, the respondents may not be truly representative of the general population in Japan. The sampling issues with webbased surveys have been described previously. ${ }^{31}$ Elderly people often have difficulty participating in such surveys. Moreover, the decision to respond to the survey may constitute selection bias, that is, the respondents who were suffering from chronic pain may have been particularly interested in pain research.

\section{Conclusion}

ELA was associated with a higher prevalence of chronic pain in both sexes, and with chronic multisite pain and somatizing tendency among women with chronic pain in the Japanese general population.

\section{Acknowledgments}

We are grateful to Dr. Yasuo Takagi, professor of Keio University, Japan, for his valuable help in conducting the survey. We also express our appreciation to all of the participants of this study, and we thank Dr. Masayuki Yao, psychiatrist of Ranryo Hospital, Japan, and Dr. Kenta Wakaizumi, Keio University, Japan, for their professional advice.

\section{Disclosure}

The authors report no conflict of interest in this work.

\section{References}

1. Chalavi S, Vissia EM, Giesen ME, et al. Abnormal hippocampal morphology in dissociative identity disorder and post-traumatic stress disorder correlates with childhood trauma and dissociative symptoms. Hum Brain Mapp. 2015;36(5):1692-1704.

2. Bradford K, Shih W, Videlock EJ, et al. Association between early adverse life events and irritable bowel syndrome. Clin Gastroenterol Hepatol. 2012;10(4):385-390.

3. Boisset-Pioro MH, Esdaile JM, Fitzcharles MA. Sexual and physical abuse in women with fibromyalgia syndrome. Arthritis Rheum. 1995; 38(2):235-241.

4. Filippon APM, Bassani DG, Aguiar RW de, Ceitlin LHF. Association between childhood trauma and loss of functionality in adult women with fibromyalgia. Trends Psychiatry Psychother. 2013;35(1):46-54.

5. Schofferman J, Anderson D, Hines R, Smith G, Keane G. Childhood psychological trauma and chronic refractory low-back pain. Clin J Pain. 1993;9(4):260-265.

6. Taylor ML, Trotter DR, Csuka ME. The prevalence of sexual abuse in women with fibromyalgia. Arthritis Rheum. 1995;38(2):229-234.

7. Jones GT, Power C, Macfarlane GJ. Adverse events in childhood and chronic widespread pain in adult life: results from the 1958 British Birth Cohort Study. Pain. 2009;143(1-2):92-96.

8. Stickley A, Koyanagi A, Kawakami N; WHO World Mental Health Japan Survey Group. Childhood adversities and adult-onset chronic pain: results from the world mental health survey, Japan. Eur J Pain. 2015;19(10):1418-1427.

9. Davis MC, Matthews KA, Twamley EW. Is life more difficult on Mars or Venus? a meta-analytic review of sex differences in major and minor life events. Ann Behav Med. 1999;21(1):83-97.
10. Craft RM, Mogil JS, Maria Aloisi A. Sex differences in pain and analgesia: the role of gonadal hormones. Eur J Pain. 2004;8:397-411.

11. Woodrow KM, Friedman GD, Siegelaub AB, Collen MF. Pain tolerance: differences according to age, sex and race. Psychosom Med. 1972;34(6): 548-556.

12. Yunus MB. The role of gender in fibromyalgia syndrome. Curr Rheumatol Rep. 2001;3(2):128-134.

13. Barsky AJ, Peekna HM, Borus JF. Somatic symptom reporting in women and men. J Gen Intern Med. 2001;16(4):266-275.

14. Yamada K, Matsudaira K, Takeshita K, Oka H, Hara N, Takagi Y. Prevalence of low back pain as the primary pain site and factors associated with low health-related quality of life in a large Japanese population: a pain-associated cross-sectional epidemiological survey. Mod Rheumatol. 2013:1-8.

15. Yamada K, Matsudaira K, Imano H, Kitamura A, Iso H. Influence of work-related psychosocial factors on the prevalence of chronic pain and quality of life in patients with chronic pain. BMJ Open. 2016; 6(4):e010356.

16. Japanese Ministry of Internal Affairs and Communications. the Japanese demographic composition in 2007; 2007. Available from: http://www. stat.go.jp/data/jinsui/2007np/index.htm. Accessed March 14, 2015.

17. Treede R, Rief W, Barke A, et al. A classification of chronic pain for ICD-11. Pain. 2015;156(6):1003-1007.

18. Croft P, Blyth FM, van der Windt D. Number of pain sites-a simple measure of population risk? In: Chronic Pain Epidemiology: from Aetiology to Public Health. 1st ed. New York, NY: Oxford University Press; 2010:71-79.

19. Clinic M. Somatic symptom disorder - Mayo Clinic; 2015. Available from: http:/www.mayoclinic.org/diseases-conditions/somaticsymptom-disorder/basics/definition/con-20124065. Accessed May 3, 2016.

20. Derogatis LR, Melisaratos N. The brief symptom inventory: an introductory report. Psychol Med. 1983;13(3):595-605.

21. Yamazaki S, Fukuhara S, Green J. Usefulness of five-item and threeitem mental health inventories to screen for depressive symptoms in the general population of Japan. Health Qual Life Outcomes. 2005;3:48.

22. Fukuhara S, Bito S, Green J, Hsiao A, Kurokawa K. Translation, adaptation, and validation of the SF-36 health survey for use in Japan. J Clin Epidemiol. 1998;51(11):1037-1044.

23. Anda R, Tietjen G, Schulman E, Felitti V, Croft J. Adverse childhood experiences and frequent headaches in adults. Headache. 2010;50(9): 1473-1481.

24. Frodl T, Reinhold E, Koutsouleris N, Reiser M, Meisenzahl EM. Interaction of childhood stress with hippocampus and prefrontal cortex volume reduction in major depression. J Psychiatr Res. 2010;44(13): 799-807.

25. Gorka AX, Hanson JL, Radtke SR, Hariri AR. Reduced hippocampal and medial prefrontal gray matter mediate the association between reported childhood maltreatment and trait anxiety in adulthood and predict sensitivity to future life stress. Biol Mood Anxiety Disord. 2014; $4: 12$.

26. Mutso AA, Radzicki D, Baliki MN, et al. Abnormalities in hippocampal functioning with persistent pain. J Neurosci. 2012;32(17):5747-5756.

27. Woolf CJ. Central sensitization: implications for the diagnosis and treatment of pain. Pain. 2011;152(3 Suppl):S2-S15.

28. Bartley EJ, King CD, Sibille KT, et al. Enhanced pain sensitivity among individuals with symptomatic knee osteoarthritis: potential sex differences in central sensitization. Arthritis Care Res (Hoboken). 2016;68(4):472-480.

29. Croft P, Blyth FM, van der Windt D. Life-course influences on chronic pain in adults. In: Chronic Pain Epidemiology: from Aetiology to Public Health. 1st ed. New York, NY: Oxford University Press; 2010:177-183.

30. Rao U, Chen L-A, Bidesi AS, Shad MU, Thomas MA, Hammen CL. Hippocampal changes associated with early-life adversity and vulnerability to depression. Biol Psychiatry. 2010;67(4):357-364.

31. Rhodes SD, Bowie DA, Hergenrather KC. Collecting behavioural data using the world wide web: considerations for researchers. J Epidemiol Community Health. 2003;57(1):68-73. 
The Journal of Pain Research is an international, peer reviewed, open access, online journal that welcomes laboratory and clinical findings in the fields of pain research and the prevention and management of pain. Original research, reviews, symposium reports, hypothesis formation and commentaries are all considered for publication
The manuscript management system is completely online and includes a very quick and fair peer-review system, which is all easy to use. Visit http://www.dovepress.com/testimonials.php to read real quotes from published authors. 